\title{
NOTA
}

\section{TOLERÂNCIA DE PERDA DE SOLO POR EROSÃO PARA OS PRINCIPAIS SOLOS DO ESTADO DE SANTA CATARINA(1)}

\author{
I. BERTOL ${ }^{(2)}$ \& J . A. ALMEIDA(3)
}

\begin{abstract}
RESUMO
A tolerância de perda de solo por erosão refere-se a um limite de perda que ainda mantenha alto nível de produtividade das culturas, econômica e indefinidamente, podendo ser utilizada na E quação Universal de Perda de Solo, além da forma usual, como um critério para definir a distância entre terraços numa lavoura. Este trabalho foi desenvolvido no Centro de Ciências Agroveterinárias de Lages (SC), em 1998, com o objetivo de estabelecer a tolerância de perda de solo por erosão hídrica para 73 perfis de solo do estado de Santa Catarina, agrupados em 19 classes, utilizando três métodos. 0 Método I, baseado na profundidade efetiva do solo e na relação textural entre os horizontes B e A; o Método II, para o qual se incluiu no Método I o teor de argila no horizonte A, e o Método III, para o qual se incluiu no Método II o teor de matéria orgânica na camada de $0-20 \mathrm{~cm}$ e o grau de permeabilidade do solo. Os valores de tolerância de perda de solo variaram de 0,15 a $1,16 \mathrm{~mm}$ ano-1 (equivalente a 1,88 a 14,50 Mg ha ano-1, respectivamente) para os solos estudados, dependendo do tipo de solo e do método utilizado na estimativa. Os Latossolos (com exceção do Bruno/Roxo), Podzólicos, Terras Brunas Estruturadas, Cambissolos e Areias Quartzozas apresentaram menor tolerância de perda de solo pelo Método III, enquanto os Litólicos, Brunizém Avermelhado, Terras Vermelha/Brunada e Roxa Estruturadas e Latossolo Bruno/Roxo apresentaram a mesma tolerância de perda de solo em todos os métodos estudados, razão por que, para estes solos, pode ser usado qualquer um dos métodos para estimar sua tolerância.
\end{abstract}

Termos de indexação: Equação Universal de Perda de Solo, profundidade efetiva, relação textural, taxa de erosão.

(1) Trabalho desenvolvido com recursos parciais do CAV/UDESC. Apresentado na II Reunião Sul Brasileira de Ciência do Solo, Santa Maria (RS), 1998. Recebido para publicação em fevereiro de 1999 e aprovado em maio de 2000.

(2) Engenheiro-Agrônomo, Professor do Departamento de Solos da Universidade do Estado de Santa Catarina - CAV/UDESC, Caixa Postal 281, CEP 88520-000 Lages (SC). Bolsista do CNPq. E-mail a2ib@cav.udesc.br

(3) Engenheiro-Agrônomo, Professor do Departamento de Solos, CAV/UDE SC. Bolsista do CNPq. E-mail a2jaa@cav.udesc.br 


\title{
SUMMARY: SOIL LOSS TOLERANCE BY EROSION FOR SANTA CATARINA STATE SOILS
}

\begin{abstract}
Soil loss tolerancerefers to themaximum rate of annual soil loss that will permit crop productivity to be obtained economically and indefinitely. Besides the usual form, it can also beused in theUniversal Soil Loss Equation as a criteria to better defineterracespacing on croplands. This research work was devel oped during 1998, at theAgroveterinary Center/ UDESC, in Lages, Santa Catarina, Brazil, to establish soil loss tol erance values by water erosion for 73 soil profiles of Santa Catarina, grouped within 19 taxonomic classes, and using threemethods: (a) Method I, based on both rooting depth and textural ratio between $B$ and A horizons; (b) Method II, similar to Method I, plus the clay content in the A horizon; and (c) Method III, simi lar to Method II, plus theorganic matter content in the $0-20 \mathrm{~cm}$ soil depth and the soil permeability of the soil profile. Tolerance values for the studied soils varied from 0.15 to $1.16 \mathrm{~mm}_{\text {year }}{ }^{-1}$, depending on both soil type and estimation method. Latosols (except for the brown/ reddish), Podzolic soils, brown structured earth, Cambi sols, and Quartz sands showed lower values of soil loss tol eranceby method III - which is suggested for estimating T-values for these soils - than methods I and II. Litolic soils, brunizens, red and brown/ reddish structured earth, and brown/ reddish L atosols showed similar soil l oss tolerance values, regardless of the method used. Therefore, for these soils, any of the three methods studied can be used for estimating soil loss tol erancevalues.
\end{abstract}

Index terms: Universal Soil Loss E quation, soil loss tolerance, effective soil depth, textural relation, erosion rate.

\section{INTRODUÇÃO}

O conceito de tolerância de perda de solo por erosão tem sido modificado ao longo do tempo. I nicialmente, ele foi relacionado com a taxa média de intemperização do solo, tendo sido estabel ecido, pela primeira vez, em 1908, por Chamberlin \& Bennet (J ohnson, 1987). Smith (1941) foi provavelmente o primeiro estudioso de erosão a estabelecer um conceito para a tolerância de perda de solo. Segundo o autor, a taxa máxima de perda de solo permitida seria aquela que garantisse a manutenção da fertilidade do solo no tempo. Reconheceu, no entanto, que o aspecto econômico deveria também ser levado em conta no estabel ecimento dos limites de perda de solo. Para Smith \& Whitt (1948), o objetivo final da conservação do solo era manter indefinidamente sua fertilidade e capacidade produtiva.

A tolerância de perda de solo por erosão pode referir-se a um limite de perda queainda mantenha al to nível de produtividade das culturas, econômica e indefinidamente (Wischmeier \& Smith, 1978; J ohnson, 1987), ou, ainda, à profundidade do solo, taxa de erosão presente e aspectos sociais ou econômicos presentes e futuros, os quais permitem avaliar a degradação do solo por meio da mudança de sua profundidade (Sparovek \& van Lier, 1997). As informações sobre tolerância de perda de solo podem ser utilizadas na E quação Universal dePerda de Solo (USLE) (Wischmeier \& Smith, 1978) e
Equação Universal de Perda de Solo Revisada (RUSLE) (Renard et al., 1997), além da forma usual para testar a eficácia dos sistemas de manejo do solo, como um critério para definir a distância entre terraços numa lavoura.

Nos estudos de tolerância de perda para os solos do estado de São Paulo, desenvol vidos por Lombardi Neto \& Bertoni (1975) e por Freire \& Vasques Filho (1978), especificamente para os solos de Piracicaba (SP), foram levadas em conta a profundidade efetiva do solo e a relação textural dos horizontes superficiais. Galindo \& Margolis (1989), estudando solos do estado de Pernambuco, incluíram nestes critérios o teor de matéria orgânica e o grau de permeabilidade do solo.

Para as condições dos Estados Unidos, Smith (1941) considerou que perdas de solo de $9,0 \mathrm{Mg}^{\mathrm{g}}$ h-1 ano-1 seriam excessivas, não mantendo a fertilidade dos sol os do estado de Wisconsin. Browning et al. (1947) admitiram que uma tolerância de $11,0 \mathrm{Mg} \mathrm{ha}^{-1}$ ano-1 $^{-1}$ ainda seria permitida naquele país, sem diminuir a produtividade e protegendo o solo contra voçorocas. Ainda nos EUA, Smith \& Whitt (1948) estabeleceram que não se poderia permitir uma perda maior do que 6,7 a 9,0 $\mathrm{Mg} \mathrm{ha}^{-1} \mathrm{ano}^{-1}$ para manter indefinidamentea fertilidade, dependendo dotipo desol o. A tolerância média de perda estabelecida por Lombardi Neto \& Bertoni (1975), para solos do estado deSão Paulo, variou de 4,5 a 13,4 e de 9,6 a 15,0 $\mathrm{Mg} \mathrm{ha}^{-1}$ ano-1, $^{-1}$ para sol os com horizontes B textural eB latossólico, respectivamente. Freire \& Vasques Filho (1978) 
definiram limites de perda de solo para Piracicaba (SP), variando de 1,8 a $15,7 \mathrm{Mg} \mathrm{ha}^{-1} \mathrm{ano}^{-1}$. Os estudos de Galindo \& Margolis (1989) indicaram perdas toleráveis, variando de 1,1 a $12,3 \mathrm{Mg} \mathrm{ha}^{-1}$ ano-1 (considerando uma densidade do solo média de $\left.1,25 \mathrm{~g} \mathrm{~cm}^{-3}\right)$, para os sol os do estado de Pernambuco, dependendo do sol o e do método utilizado no cál culo.

Os métodos de estimativa da tolerância de perda de solo por erosão, embora utilizem atributos e características que influenciam a erosão do solo e tenham uma base de sustentação lógica e racional, são empíricos, notadamente no que se refere à definição dos fatores de ponder ação utilizados para expressar o efeito de cada variável, o que conduz a estimativas detolerância diferentes para um mesmo solo. Aliado a isso, não há ainda um consenso entre os pesquisadores sobre o nível detolerância de perda desolo. Assim, torna-seimportante definir a tolerância para diferentes classes de solo, mesmo por métodos empíricos, com vistas em monitorar a eficácia dos sistemas de manejo do solo na redução da erosão.

Considerando a inexistência de dados sobre os valores de tolerância de perda de solo por erosão para os sol os do estado de Santa Catarina, bem como a falta de um consenso acerca do mel hor método para estimá-los, o presente trabalho objetivou definir a tolerância de perda para os principais solos catarinenses, tomando como referencial o método proposto por Lombardi Neto \& Bertoni (1975). A partir daí, foram propostos métodos alternativos para estimar essas tolerâncias, pela introdução de novas variáveis efatores de ponderação, comparando sua eficácia relativa aos valores das tolerâncias obtidos para os diversos perfis de solo estudados. Assim, o objetivo do trabalho foi não só estimar a tolerância de perda de solo por erosão hídrica para os principais solos do estado de Santa Catarina, utilizando três métodos baseados na profundidade efetiva do solo, relação textural entre os horizontes $B$ e A, teor de argila no horizonte A, teor de matéria orgânica na camada de $0-20 \mathrm{~cm}$ de profundidade e grau de permeabilidade do solo, mas também comparar os métodos entre si.

\section{MATE RIAL E MÉTODOS}

O trabalho foi realizado, em 1998, no Centro de Ciências Agroveterinárias da Universi dade do estado de Santa Catarina (UDESC), localizado em Lages (SC), consistindo no estudo de 73 perfis de solos representativos do estado de Santa Catarina, distribuídos em 19 dasses (Quadro 1). Os referidos perfis estão descritos em UFSM (1973), Almeida \& Bertol (1987), Bognola (1995), Almeida \& Maçaneiro (1996), Almeida (1997), Almeida et al. (1997) el BGE (S/D)(4).

As tolerâncias de perda de sol o foram cal culadas por meio de três métodos: Métodol, proposto por Lombardi Neto \& Bertoni (1975); Método II, correspondente ao Método I modificado pelos autores, e Método III, correspondente ao método proposto por Galindo \& Margolis (1989), também modificado pel os autores.

Em cada um dos três métodos, foram utilizadas a profundidade efetiva do solo (Quadro 2) ea relação textural entre os horizontes B e A (Quadro 3), conforme critérios gerais estabelecidos por Lombardi Neto \& Bertoni (1975), como variáveis importantes na estimativa da tolerância de perda de solo por erosão hídrica. Considerou-se como profundidade efetiva, medi da em metro, a camada de sol o favorável ao desenvolvimento do sistema radicular das plantas cultivadas. Para efeito de cálculo, sempre que a profundidade efetiva de determinado perfil de solo constante no quadro 2 era maior do que um metro, ela foi limitada a um metro, limitando-se também aos horizontes $\mathrm{A}$ e $\mathrm{B}$, mas excluindo-se os horizontes $\mathrm{B}_{3}$ ou BC.

\section{Método I}

A tolerância de perda de solo por erosão hídrica no Método I foi calculada por meio da expressão utilizada por Lombardi Neto \& Bertoni (1975), ou seja:

$$
\mathrm{T}=\mathrm{h} \mathrm{r} 1.000^{-1}
$$

em que

$\mathrm{T}=$ tolerância de perda de solo $\left(\mathrm{mm}_{\mathrm{nno}}^{-1}\right)$;

$\mathrm{h}=$ profundidade efetiva do solo $(\mathrm{mm})$, limitada a $1.000 \mathrm{~mm}$;

$r=$ quociente que expressa o efeito da relação textural entreos horizontes $B$ eA na ponderação das perdas de solo $\left(\mathrm{g} \mathrm{kg}^{-1}\right)\left(\mathrm{g} \mathrm{kg}^{-1}\right)^{-1}$, e

$1.000=$ constante que expressa o período de tempo necessário para desgastar uma camada de solo de $1.000 \mathrm{~mm}$ de espessura, desconsiderando a formação do solo nesse período, seguindo o mesmo procedimento adotado por Lombardi Neto \& Bertoni (1975). A suposição de que uma camada de solo de um metro de espessura é desgastada a cada mil anos, desconsiderando a reposição natural de solo, explica o procedimento de limitar a profundidade efetiva do solo a um metro ou mil milímetros no cálculo das tolerâncias de perda de solo.

\footnotetext{
(4) FUNDAÇÃO INSTITUTO BRASILEIRO DE GEOGRAFIA E ESTATÍSTICA. Levantamento de Recursos Naturais: Folha SG 21/22/23, Curitiba/Assunción/l guape. Volume 35. Capítulo 3 - Pedologia. Levantamento Exploratório de Solos. Rio de J aneiro. SEPLAN - FUNDAÇÃO IBGE, S/D. (Relatório técnico não publicado)
} 
Quadro 1. Classes de solo representativas do estado de Santa Catarina e número de perfis estudados por classe, utilizados na estimativa das tolerâncias de perda de solo

\begin{tabular}{|c|c|}
\hline Classe de solo & № de perfis \\
\hline \multicolumn{2}{|l|}{ Solos com horizonte B latossólico } \\
\hline Latossolo Bruno textura muito argilosa (LB) & 2 \\
\hline Latossolo Bruno/Roxo textura muito argilosa (LBR) & 3 \\
\hline Latossolo Roxo textura muito argilosa (LR) & 2 \\
\hline Latossolo Vermel ho-E scuro textura muito argilosa (LE) & 4 \\
\hline Latossolo Vermel ho-Amarelo textura argilosa (LV) & 3 \\
\hline \multicolumn{2}{|l|}{ Solos com horizonte B textural } \\
\hline Podzólico Vermelho-Amarelo textura média/argilosa e argilosa/muito argil osa (PV) & 10 \\
\hline Podzólico Vermel ho-E scuro textura média/argil losa (PE) & 3 \\
\hline Terra Bruna Estruturada textura muito argilosa (TB) & 6 \\
\hline Terra Bruna/Roxa Estruturada textura argilosa e muito argilosa (TBR) & 3 \\
\hline Terra Vermelha/Brunada Estruturada textura muito argi losa (TVB) & 3 \\
\hline Terra Roxa Estruturada textura argilosa e muito argilosa (TR) & 2 \\
\hline Brunizém Avermel hado textura média/argilosa (BV) & 2 \\
\hline \multicolumn{2}{|l|}{ Solos com horizonte B incipiente } \\
\hline Cambissolo Húmico textura argilosa e muito argilosa $(\mathrm{CH})$ & 10 \\
\hline Cambissolo eutrófico textura argilosa (Ce) & 2 \\
\hline Cambissolo Bruno Húmico textura argi losa e muito argilosa (CBH) & 2 \\
\hline Cambissolo textura argilosa e muito argilosa (C) & 5 \\
\hline \multicolumn{2}{|l|}{ Solos pouco desenvolvidos } \\
\hline Litólico Húmico textura média e argilosa (RH) & 4 \\
\hline Litólico textura média e argilosa (R) & 3 \\
\hline Areia Quartzoza (AQ) & 4 \\
\hline Total & 73 \\
\hline
\end{tabular}

Quadro 2. Profundidade efetiva real dos perfis de solo estudados (tendo sido limitada a um metro sua utilização no cálculo das tolerâncias de perda de solo)

\begin{tabular}{|c|c|c|c|c|c|c|c|c|c|c|c|}
\hline \multirow{2}{*}{ Classe } & \multicolumn{10}{|c|}{ Número de perfis } & \multirow{2}{*}{ Média } \\
\hline & 1 & 2 & 3 & 4 & 5 & 6 & 7 & 8 & 9 & 10 & \\
\hline & & & & & & & & & & & \\
\hline LB & 2,75 & 2,20 & - & - & - & - & - & - & - & - & 2,48 \\
\hline LBR & 3,05 & 1,28 & 1,80 & - & - & - & - & - & - & - & 2,04 \\
\hline LR & 2,20 & 2,50 & - & - & - & - & - & - & - & - & 2,35 \\
\hline LE & 1,60 & 2,10 & 2,05 & 2,00 & - & - & - & - & - & - & 1,94 \\
\hline LV & 2,30 & 1,32 & 1,30 & - & - & - & - & - & - & - & 1,64 \\
\hline PV & 1,10 & 0,80 & 0,90 & 0,70 & 1,32 & 1,27 & 1,10 & 1,20 & 0,80 & 1,06 & 1,03 \\
\hline PE & 1,72 & 2,20 & 1,58 & - & - & - & - & - & - & - & 1,83 \\
\hline TB & 1,50 & 1,45 & 1,90 & 1,55 & 2,00 & 4,50 & - & - & - & - & 2,15 \\
\hline TBR & 1,90 & 1,00 & 0,90 & - & - & - & - & - & - & - & 1,27 \\
\hline TVB & 1,05 & 2,30 & 1,80 & - & - & - & - & - & - & - & 1,72 \\
\hline TR & 1,50 & 1,30 & - & - & - & - & - & - & - & - & 1,40 \\
\hline BV & 0,60 & 1,50 & - & - & - & - & - & - & - & - & 1,05 \\
\hline $\mathrm{CH}$ & 1,00 & 1,05 & 0,85 & 0,70 & 0,98 & 0,74 & 1,15 & 1,10 & 0,90 & 1,23 & 0,97 \\
\hline $\mathrm{Ce}$ & 1,05 & 0,70 & - & - & - & - & - & - & - & - & 0,88 \\
\hline $\mathrm{CBH}$ & 1,30 & 0,75 & - & - & - & - & - & - & - & - & 1,03 \\
\hline C & 1,35 & 0,87 & 0,90 & 1,20 & 0,70 & - & - & - & - & - & 1,00 \\
\hline $\mathrm{RH}$ & 0,20 & 0,55 & 0,29 & 0,18 & - & - & - & - & - & - & 0,31 \\
\hline $\mathrm{R}$ & 0,18 & 0,50 & 0,25 & - & - & - & - & - & - & - & 0,31 \\
\hline$A Q$ & 0,50 & 0,28 & 0,26 & 0,25 & - & - & - & - & - & - & 0,32 \\
\hline
\end{tabular}

LB, LBR, LR, LE e LV: Latossolos Bruno, Bruno/Roxo, Roxo, Vermelho-Escuro e Vermelho-Amarelo, respectivamente; PV e PE: Podzólicos Vermelho-Amarelo e Vermelho-Escuro, respectivamente; TB, TBR, TVB e TR: Terras Bruna, Bruna/Roxa, Vermelha/ Brunada e Roxa Estruturadas, respectivamente; BV: Brunizém Avermel hado; $\mathrm{CH}$, Ce, $\mathrm{CBH}$ e C: Cambissol os Húmicos eutróficos e Bruno Húmico, e Cambissolo, respectivamente; RH e R: Litólico Húmico e Litólico, respectivamente; AQ: Areia Quartzoza. 
Quadro 3. Relação textural entre os horizontes B eA dos perfis de solo estudados, utilizada para estabelecer os valores de ponderação usados no cálculo das tolerâncias de perda de solo

\begin{tabular}{|c|c|c|c|c|c|c|c|c|c|c|c|}
\hline \multirow{2}{*}{ Classe } & \multicolumn{10}{|c|}{ Número de perfis } & \multirow{2}{*}{ Média } \\
\hline & 1 & 2 & 3 & 4 & 5 & 6 & 7 & 8 & 9 & 10 & \\
\hline & \multicolumn{11}{|c|}{$-\left(\mathrm{g} \mathrm{kg}^{-1}\right)\left(\mathrm{g} \mathrm{kg}^{-1}\right)^{-1}$} \\
\hline LB & 1,06 & 1,00 & - & - & - & - & - & - & - & - & 1,03 \\
\hline LBR & 1,16 & 1,07 & 1,07 & - & - & - & - & - & - & - & 1,10 \\
\hline LR & 1,15 & 1,16 & - & - & - & - & - & - & - & - & 1,16 \\
\hline LE & 0,96 & 1,08 & 1,18 & 0,99 & - & - & - & - & - & - & 1,05 \\
\hline LV & 1,16 & 1,47 & 1,00 & - & - & - & - & - & - & - & 1,21 \\
\hline PV & 1,61 & 1,44 & 1,51 & 1,41 & 1,47 & 1,28 & 1,53 & 1,55 & 1,89 & 1,53 & 1,52 \\
\hline $\mathrm{PE}$ & 1,81 & 1,71 & 1,48 & - & - & - & - & - & - & - & 1,67 \\
\hline TB & 1,19 & 1,07 & 1,07 & 0,90 & 1,16 & 1,00 & - & - & - & - & 1,06 \\
\hline TBR & 0,97 & 1,45 & 1,40 & - & - & - & - & - & - & - & 1,27 \\
\hline TVB & 1,06 & 1,18 & 1,20 & - & - & - & - & - & - & - & 1,15 \\
\hline $\mathrm{TR}$ & 1,52 & 1,50 & - & - & - & - & - & - & - & - & 1,51 \\
\hline BV & 1,16 & 1,53 & - & - & - & - & - & - & - & - & 1,35 \\
\hline $\mathrm{CH}$ & 1,34 & 1,14 & 1,17 & 1,16 & 1,16 & 1,05 & 1,43 & 1,13 & 1,11 & 1,02 & 1,17 \\
\hline $\mathrm{Ce}$ & 1,08 & 0,97 & - & - & - & - & - & - & - & - & 1,03 \\
\hline $\mathrm{CBH}$ & 1,44 & 1,17 & - & - & - & - & - & - & - & - & 1,31 \\
\hline C & 1,47 & 1,14 & 1,37 & 1,29 & 1,48 & - & - & - & - & - & 1,35 \\
\hline $\mathrm{RH}$ & 2,06 & 1,49 & 2,09 & 2,11 & - & - & - & - & - & - & 1,94 \\
\hline $\mathrm{R}$ & 2,10 & 1,49 & 2,09 & - & - & - & - & - & - & - & 1,89 \\
\hline $\mathrm{AQ}$ & 1,25 & 1,18 & 1,15 & 1,08 & - & - & - & - & - & - & 1,17 \\
\hline
\end{tabular}

LB, LBR, LR, LE e LV: Latossolos Bruno, Bruno/Roxo, Roxo, Vermelho-Escuro e Vermel ho-Amarelo, respectivamente; PV e PE: Podzólicos Vermelho-Amarelo e Vermelho-E scuro, respectivamente; TB, TBR, TVB e TR: Terras Bruna, Bruna/Roxa, Vermelha/ Brunada e Roxa Estruturadas, respectivamente; BV: Brunizém Avermel hado; $\mathrm{CH}, \mathrm{Ce}, \mathrm{CBH}$ e C: Cambissol os Húmicos eutróficos e Bruno Húmico, e Cambissolo, respectivamente; RH e R: Litólico Húmico e Litólico, respectivamente; AQ: Areia Quartzoza.

Para uma relação textural inferior a 1,5, a tolerância de perda de solo de determinado perfil foi obtida multiplicando-se a profundidade efetiva do referido perfil constante no quadro 2 (limitada a um metro) por um valor $r$ igual a 1,00 (resultando em $100 \%$ da profundidade efetiva do solo, limitada a um metro). Quando a relação textural foi de 1,5 a 2,5 , o valor de $r$ utilizado na multiplicação foi 0,75 (resultando em $75 \%$ da profundidade efetiva) e, quando superior a 2,5, utilizou-se na multiplicação um valor $r$ igual a 0,50 (resultando em $50 \%$ da referida profundidade). A relaçãotextural foi obtida por meio do quociente entre o teor médio de argila do horizonte $\mathrm{B}$ (excluindo-se o $\mathrm{B}_{3}$ ou $\mathrm{BC}$ ) e o teor médio de argila do horizonte $A$.

Para os Litólicos, nos quais o horizonte B não está presente, adotaram-se valores de $r$ de 0,75 e 0,50, quando o horizonte A ocorria acima do horizonte C ou diretamente sobre a rocha, respectivamente, já que essa condição limita a quantidade de água infiltrada no solo.

Para as Areias Quartzozas, as quais também não possuem horizonte $B$, adotou-se um valor para $r$ igual a 1,00, por ser a variação noteor deargila de $A$ para $C$ muito pequena em relação às demais classes de solo estudadas, o que favorece a infiltração da água no solo. Assim, para os perfis das duas classes de Litólicos e das Areias Quartzozas, os valores de relação textural expressos no quadro 3 foram arbitrados, uma vez que não podiam ser calculados como nos demais perfis de solos.

Considerando que, em mesma classe de solo, os perfis apresentaram diferentes profundidades efetivas reais (Quadro 2), oval or médio da tol erância de perda de solo da referida classe foi estimado, ponderando-se a soma das tolerâncias obtidas para cada perfil da classe de acordo com sua profundidade efetiva real edividindo-se oval or obtido pel o número de perfis da classe. Esse valor foi multiplicado pela profundidade efetiva real média da classe. Para a classe de solo PE, por exemplo, utilizando os dados de profundidade efetiva (Quadro 2) e tolerância de perda de sol o pel o Método I (Quadro 4), procedeu-se ao seguinte cálculo para estimar o seu valor médio de tolerância de perda de solo por este método:

$$
\begin{gathered}
\text { Tolerância média } \text { (mmano-1) }=\{[(0,75 / 1,72)+(0,75 / 2,20)+ \\
+(1,00 / 1,58)] / 3\} 1,83=0,86 .
\end{gathered}
$$

Embora se reconheça a fragilidade dos pressupostos utilizados no cál culo da tolerância de perda, os quais não levam em conta a taxa de 
formação do sol o e devem ser questionados quanto ao aspecto de sustentabilidade do solo em sistemas agrícolas, eles foram utilizados, conforme método sugerido por Lombardi Neto \& Bertoni (1975).

\section{Método I I}

A tolerância de perda de sol o por esse método foi calculada por uma expressão similar à do Métodol , modificada pelos autores pela alteração dos limites de intervalos da relação textural entre os horizontes B e A e pela introdução do teor de argila do horizonte $\mathrm{A}$ como variável associada à relação textural, resultando em novos val ores para a variável $r$ do Método I, redenominada, neste método de $r_{a}$, segundo a expressão:

$$
\mathrm{T}=\mathrm{h} \mathrm{r}_{\mathrm{a}} 1.000^{-1}
$$

em que

$\mathrm{T}, \mathrm{h}, 1.000=$ mesma definição expressa no Método I e

$r_{a}=$ relação que expressa, conjuntamente, o efeito da relação textural entre os horizontes $B$ eA e do teor de argila do horizonte $A$.

Para uma relação textural inferior a 1,5 , os val ores der $r_{\text {a }}$ utilizados foram 1,0, 0,9 e 0,8, para sol os com teor de argila no horizonte A maior que $40 \%$, entre 40 e $20 \%$ e menor que $20 \%$, respectivamente. Quando a relação textural sesituava entre 1,5 e2,0, $r_{a}$ assumiu valores de 0,8, 0,7 e 0,6 e, quando a relação textural foi maior que 2,0 , os valores de $r_{a}$ foram 0,6, 0,5 e 0,4, para os mesmos intervalos de teores de argila anteriormente referidos.

Os intervalos de relação textural utilizados por Lombardi Neto \& Bertoni (1975) foram modificados com base no entendimento de que faixas de val ores derelaçãotextural entre 1,5 e 2,5 são excessivamente largas, não discriminando adequadamente solos cujos limites de tolerância de perdas devem ser diferentes. Além disso, o teor de argila do horizonte A associado à relação textural foi adotado, tendo em vista que apenas a relação textural entre os horizontes B e A pode não ser suficientemente sensível para discriminar solos com diferentes tolerâncias de perda. É o caso, por exemplo, de Latossolos Roxos de textura muito argilosa e Latossolos Vermelho-Escuros de textura média, os quais, pela expressão proposta por Lombardi Neto \& Bertoni (1975), terão tolerâncias praticamente idênticas, uma vez que ambos apresentam baixa relação textural e grande profundidade efetiva. Várias experiências de uso agrícola dos Latossolos de textura média no Brasil, entretanto, têm demonstrado quetais sol os são muito mais instáveis aos agentes erosivos do que os Latossolos Roxos. O mesmo raciocínio éváli do para sol os com horizonte $B$ textural, cuja relaçãotextural entre os horizontes $B$ e A pode ser alta em todos os perfis, mas cuja suscetibilidade à erosão hídrica pode ser muito diferente, dependendo da textura do horizonte superficial distinta entre os referidos perfis. O critério do teor de argila do horizonteA foi incluído, ainda, porque ela é uma fração granul ométrica que influencia fortemente a resistência do solo à desagregação por erosão hídrica (Wischmeier \& Smith, 1978).

Os val ores médios de tolerância de perda de solo de cada classe foram obtidos por ponderação, como para o Método I.

\section{Método III}

Neste método, além das variáveis e fatores de ponderação adotados no Método II, foram acrescentadas duas propriedades importantes do ponto de vista da erodibilidade: o teor de matéria orgânica na camada de $0-20 \mathrm{~cm}$ de profundidade e o grau de permeabilidade do solo (Wischmeier \& Smith, 1978), conforme sugerido por Galindo \& Margolis (1989), para estimar a tolerância de perda para os mesmos sol os estudados nos Métodos I ell. No entanto, modificaram-se os valores 1,15, 1,00 e 0,85 adotados pelos últimos autores para os intervalos do teor de matéria orgânica e do grau de permeabilidade do solo, conforme a expressão a seguir:

$$
\mathrm{T}=\mathrm{h} \mathrm{r}_{\mathrm{a}} \mathrm{mp} \text { 1.000-1 }
$$

em que

$\mathrm{T}, \mathrm{h}, \mathrm{r}_{\mathrm{a}}, 1.000=$ mesma definição expressa no Método II;

$\mathrm{m}=$ fator que expressa o efeito da matéria orgânica na camada de 0-20 cm do solo e

$\mathrm{p}=$ fator que expressa o efeito da permeabilidade do solo.

Para os solos com teor de matéria orgânica na camada de 0-20 cm maior que 5,0 dag kg-1, entre 5,0 e2,5 dag kg-1 e menor do que 2,5 dag kg-1, adotaramse os valores $1,00,0,85$ e 0,70 para a variável $m$, respectivamente. Os intervalos do teor de matéria orgânica adotados neste método foram diferentes daquel es estabelecidos por Gal indo \& Margol is (1989) para os solos de Pernambuco, uma vez que os solos do sul do Brasil apresentam teores mais el evados de matéria orgânica do que os do nordeste brasileiro. Caso se utilizassem aquel es interval os, não haveria discriminação adequada entre os solos estudados, já que a maioria deles no sul do Brasil apresenta teores de matéria orgânica superiores a 2 dag kg-1.

Embora seja reconhecido o papel da matéria orgânica na agregação do solo e, portanto, seu efeito no aumento da resistência do solo à erosão hídrica, optou-se por não utilizar valores superiores à unidade, como feito por Galindo \& Margolis (1989), tornando assim a estimativa de tol erância de perda 
de solo mais conservadora para os solos estudados, em rel ação ao método utilizado por aquel es autores.

Para uma permeabilidade classificada como rápida, moderada e lenta, utilizaram-se os valores $1,00,0,85$ e 0,70 , para ofator $p$, respectivamente. 0 valor 1,00 para o grau máximo de permeabilidade (rápida ou mai or) dos sol os foi adotado, considerando que solos com maior capacidade de drenagem poderiam permitir a perda máxima por erosão, com base no fato de serem tais solos, em geral, mais profundos emais bem estruturados do que os demais. Os demais valores $(0,85$ e 0,70$)$ foram arbitrados, com o objetivo de diferenciar os níveis de tolerância de perda por erosão hídrica para sol os com distintos graus de permeabilidade.

A permeabilidade de cada horizonte dos perfis estudados baseou-se em informações de textura e grau de desenvolvimento da estrutura do solo nos respectivos horizontes, enquanto a classe de drenagem do solo baseou-se em informações determinadas em campo ou obtidas da literatura consultada e citada anteriormente.

Os valores médios de tolerância de perda para cada classe de solo foram obtidos por ponderação, como para os Métodos I e II.
Os valores de tol erância de perda de solo obtidos pelos três métodos foram comparados entre si pelo teste de Duncan a 5\% de significância, apesar de conterem diferentes números de repetições ( $\mathrm{n}$ o de perfis estudados), adotando um procedimento sugerido por Gomes (1985).

\section{RESULTADOS E DISCUSSÃO}

As tolerâncias de perda de solo obtidas pelo Método I (Quadro 4), na média dos perfis estudados, variaram conforme a profundidade efetiva do solo (Quadro 2) ea relação textural entre os horizontes B eA (Quadro 3). Dentreos perfis desolo estudados por este método, podem-seestabelecer dois grupos distintos de val ores médios de tolerância de perda de solo (Quadro 4). U m grupo, com val ores variando de 0,20

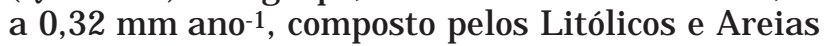
Quartzozas, e outro, com val ores variando de 0,79a $1,16 \mathrm{~mm}$ ano-1, engl obando os demais sol os estudados.

Os solos pouco desenvolvidos apresentaram os mais baixos valores de tolerância de perda de solo (Quadro 4). No caso dos Litólicos, isto deveu-se à baixa profundidade efetiva apresentada (Quadro 2),

Quadro 4. Tolerâncias de perda de solo por erosão $\left(\mathrm{mm} \mathrm{ano}^{-1}\right)$ para os perfis de solo estudados, estimadas por meio da profundidade efetiva real (Quadro 2) (limitada a um metro) e da relação textural (Quadro 3), conforme proposto no Método de Lombardi Neto \& Bertoni (1975), denominado Método I

\begin{tabular}{|c|c|c|c|c|c|c|c|c|c|c|c|c|}
\hline \multirow{2}{*}{ Classe } & \multicolumn{10}{|c|}{ Número de perfis } & \multirow{2}{*}{ Média } & \multirow{2}{*}{ Erro-pad } \\
\hline & 1 & 2 & 3 & 4 & 5 & 6 & 7 & 8 & 9 & 10 & & \\
\hline & \multicolumn{11}{|c|}{$-\mathrm{mm} \mathrm{ano}^{-1}$} & \\
\hline LB & 1,00 & 1,00 & - & - & - & - & - & - & - & - & 1,01 & 0,007 \\
\hline LBR & 1,00 & 1,00 & 1,00 & - & - & - & - & - & - & - & 1,13 & 0,075 \\
\hline LR & 1,00 & 1,00 & - & - & - & - & - & - & - & - & 1,00 & 0,000 \\
\hline LE & 1,00 & 1,00 & 1,00 & 1,00 & - & - & - & - & - & - & 1,01 & 0,005 \\
\hline LV & 1,00 & 1,00 & 1,00 & - & - & - & - & - & - & - & 1,07 & 0,040 \\
\hline PV & 0,75 & 0,80 & 0,68 & 0,70 & 1,00 & 1,00 & 0,75 & 0,75 & 0,60 & 0,75 & 0,81 & 0,040 \\
\hline $\mathrm{PE}$ & 0,75 & 0,75 & 1,00 & - & - & - & - & - & - & - & 0,86 & 0,071 \\
\hline TB & 1,00 & 1,00 & 1,00 & 1,00 & 1,00 & 1,00 & - & - & - & - & 1,16 & 0,065 \\
\hline TBR & 1,00 & 1,00 & 0,90 & - & - & - & - & - & - & - & 1,07 & 0,066 \\
\hline TVB & 1,00 & 1,00 & 1,00 & - & - & - & - & - & - & - & 1,11 & 0,064 \\
\hline $\mathrm{TR}$ & 0,75 & 1,00 & - & - & - & - & - & - & - & - & 0,89 & 0,089 \\
\hline BV & 0,60 & 0,75 & - & - & - & - & - & - & - & - & 0,79 & 0,097 \\
\hline $\mathrm{CH}$ & 1,00 & 1,00 & 0,85 & 0,70 & 0,98 & 0,74 & 1,00 & 1,00 & 0,90 & 1,00 & 0,93 & 0,035 \\
\hline $\mathrm{Ce}$ & 1,00 & 0,70 & - & - & - & - & - & - & - & - & 0,86 & 0,106 \\
\hline $\mathrm{CBH}$ & 1,00 & 0,75 & - & - & - & - & - & - & - & - & 0,91 & 0,092 \\
\hline C & 1,00 & 0,87 & 0,90 & 1,00 & 0,70 & - & - & - & - & - & 0,91 & 0,050 \\
\hline $\mathrm{RH}$ & 0,10 & 0,55 & 0,15 & 0,09 & - & - & - & - & - & - & 0,20 & 0,096 \\
\hline $\mathrm{R}$ & 0,09 & 0,50 & 0,13 & - & - & - & - & - & - & - & 0,21 & 0,108 \\
\hline $\mathrm{AQ}$ & 0,50 & 0,28 & 0,26 & 0,25 & - & - & - & - & - & - & 0,32 & 0,052 \\
\hline
\end{tabular}

LB, LBR, LR, LE e LV: Latossolos Bruno, Bruno/Roxo, Roxo, Vermelho-Escuro e Vermelho-Amarelo, respectivamente; PV e PE: Podzólicos Vermel ho-Amarelo e Vermelho-Escuro, respectivamente; TB, TBR, TVB e TR: Terras Bruna, Bruna/Roxa, Vermelha/ Brunada e Roxa Estruturadas, respectivamente; BV: Brunizém Avermel hado; $\mathrm{CH}, \mathrm{Ce}, \mathrm{CBH}$ e C: Cambissol os Húmicos eutróficos e Bruno Húmico, e Cambissolo, respectivamente; RH e R: Litólico Húmico e Litólico, respectivamente; AQ: Areia Quartzoza. 
o que limita fortemente a quantidade de água infiltrada no perfil eaumenta o risco de erosão, além de um horizonte A fraco ou moderadamente desenvolvido assentado diretamente sobre a rocha ou horizonte C. No caso das Areias Quartzozas, os conteúdos al tos de areia ebaixos de argila e matéria orgânica conferem fraca agregação, com conseqüente baixa resistência à erosão hídrica, apesar da rápida drenagem de água no perfil e da alta profundidade efetiva desses solos (Quadro 2).

Os solos com horizontes B textural e incipiente apresentaram, em geral, mai or relaçãotextural entre os horizontes B eA (Quadro 3) e baixa profundidade efetiva (Quadro 2), respectivamente, o que limita fortemente sua capacidade de drenagem, tornandoos mais suscetíveis à erosão, especialmente quando oconteúdo deareia no horizonteA éalto. Apesar disso, estes solos toleram, de modo geral, perdas médias por er osão maiores do que os sol os pouco desenvol vidos, como indicado por este método (Quadro 4).

Os sol os com horizonte B latossólico e a maioria das Terras Estruturadas apresentaram, em geral, elevada profundidade efetiva (Quadro 2). A baixa relação textural (Quadro 3) e a estrutura bem desenvolvida destes solos facilitaram a drenagem de água no perfil, fatores que, aliados à sua textura argilosa ou muito argilosa, conferem-Ihes maior resistência à erosão do que os demais. Assim, a tolerância média para estes solos teveuma tendência de ser maior do que para os sol os com horizontes $B$ textural e incipiente (Quadro 4), apesar de não ter havido diferença estatística entre el es (Quadro 7).

No Método II, os valores de tolerância de perda de solo (Quadro 5), na média dos perfis estudados, também formaram dois grupos distintos, constituídos pelos mesmos perfis que compuseram os referidos grupos no Métodol, cujos valores de tolerância, em cada um dos grupos, foram semel hantes àqueles do Método I. Assim, o grupo composto pelos Litólicos e Areias Quartzozas apresentou tolerâncias variando de 0,21 a $0,26 \mathrm{~mm}$ ano- $^{-1}$, enquanto o outro grupo, composto pel os demais sol os, apresentou valores variando de 0,72 a 1,16 mm ano-1. Para al gumas classes de solo, este método apresentou val ores médios detolerância menores do que pelo Método I, embora, na média das classes de sol oestudadas, os val ores detolerância foram semel hantes em ambos os métodos.

Os Litólicos e Areias Quartzozas no Método II, como ocorreu no Métodol, foram os queapresentaram os menores valores de tolerância dentre as classes estudadas, pelas razões já discutidas no Método I.

Quadro 5. Tolerâncias de perda de solo por erosão $\left(\mathrm{mm}^{\mathrm{ano}} \mathrm{o}^{-1}\right)$ para os perfis de solo estudados, estimadas por meio do Método proposto por Lombardi Neto \& Bertoni (1975), modificado pelos autores quanto aos intervalos da relação textural e incluído o teor de argila no horizonte A, denominado Método II

\begin{tabular}{|c|c|c|c|c|c|c|c|c|c|c|c|c|}
\hline \multirow{2}{*}{ Classe } & \multicolumn{10}{|c|}{ Número de perfis } & \multirow{2}{*}{ Média } & \multirow{2}{*}{ Erro-padrã } \\
\hline & 1 & 2 & 3 & 4 & 5 & 6 & 7 & 8 & 9 & 10 & & \\
\hline & \multicolumn{11}{|c|}{$-\mathrm{mm}$ ano-1 } & \\
\hline LB & 1,00 & 1,00 & - & - & - & - & - & - & - & - & 1,01 & 0,007 \\
\hline LBR & 1,00 & 1,00 & 1,00 & - & - & - & - & - & - & - & 1,13 & 0,075 \\
\hline LR & 1,00 & 1,00 & - & - & - & - & - & - & - & - & 1,00 & 0,000 \\
\hline LE & 1,00 & 1,00 & 1,00 & 1,00 & - & - & - & - & - & - & 1,01 & 0,005 \\
\hline LV & 1,00 & 0,90 & 0,90 & - & - & - & - & - & - & - & 0,99 & 0,043 \\
\hline PV & 0,70 & 0,72 & 0,72 & 0,63 & 0,90 & 1,00 & 0,70 & 0,70 & 0,56 & 0,70 & 0,75 & 0,038 \\
\hline PE & 0,60 & 0,70 & 0,90 & - & - & - & - & - & - & - & 0,75 & 0,073 \\
\hline TB & 1,00 & 1,00 & 1,00 & 1,00 & 1,00 & 1,00 & - & - & - & - & 1,16 & 0,065 \\
\hline TBR & 1,00 & 1,00 & 0,90 & - & - & - & - & - & - & - & 1,07 & 0,066 \\
\hline TVB & 1,00 & 1,00 & 1,00 & - & - & - & - & - & - & - & 1,11 & 0,064 \\
\hline TR & 0,70 & 1,00 & - & - & - & - & - & - & - & - & 0,87 & 0,107 \\
\hline BV & 0,54 & 0,70 & - & - & - & - & - & - & - & - & 0,72 & 0,091 \\
\hline $\mathrm{CH}$ & 1,00 & 1,00 & 0,85 & 0,70 & 0,98 & 0,74 & 0,90 & 1,00 & 0,81 & 0,90 & 0,90 & 0,034 \\
\hline $\mathrm{Ce}$ & 0,90 & 0,70 & - & - & - & - & - & - & - & - & 0,82 & 0,072 \\
\hline $\mathrm{CBH}$ & 1,00 & 0,75 & - & - & - & - & - & - & - & - & 0,91 & 0,092 \\
\hline C & 0,90 & 0,78 & 0,81 & 1,00 & 0,63 & - & - & - & - & - & 0,84 & 0,056 \\
\hline $\mathrm{RH}$ & 0,10 & 0,55 & 0,17 & 0,19 & - & - & - & - & - & - & 0,21 & 0,093 \\
\hline $\mathrm{R}$ & 0,09 & 0,50 & 0,13 & - & - & - & - & - & - & - & 0,21 & 0,108 \\
\hline$A Q$ & 0,40 & 0,22 & 0,21 & 0,20 & - & - & - & - & - & - & 0,26 & 0,041 \\
\hline
\end{tabular}

LB, LBR, LR, LE e LV: Latossolos Bruno, Bruno/Roxo, Roxo, Vermelho-Escuro e Vermelho-Amarelo, respectivamente; PV e PE: Podzólicos Vermel ho-Amarelo e Vermel ho-Escuro, respectivamente; TB, TBR, TVB e TR: Terras Bruna, Bruna/Roxa, Vermel ha/ Brunada e Roxa Estruturadas, respectivamente; BV: Brunizém Avermel hado; $\mathrm{CH}$, Ce, CBH e C: Cambissol os Húmicos eutróficos e Bruno Húmico, e Cambissolo, respectivamente; RH e R: Litólico Húmico e Litólico, respectivamente; AQ: Areia Quartzoza. 
Os Latossolos, com exceção do Vermel ho-Amarelo, e as Terras Estruturadas, com exceção da Roxa, apresentaram, pelo Método II, maior valor de tolerância de perda por erosão do que as demais classes de solo, tal como ocorreu no Método I.

Os valores médios detolerância de perda de solo obtidos pelo Método III (Quadro 6) revelaram uma distribuiçãotambém em dois grupos distintos, assim como ocorreu nos Métodos I e II. No entanto, os intervalos dos valores de tolerância no Método III foram distintos daqueles dos métodos anteriores. Assim, o grupo composto pelos Litólicos e Areias Quartzozas apresentou valores de tolerância variando de 0,15 a 0,18 mm ano-1, enquanto o outro grupo, composto pelos demais solos, apresentou val ores variando de 0,52 a $1,13 \mathrm{~mm}^{2} \mathrm{ano}^{-1}$. I stoindica que este método apresentou, para al gumas classes de solo, valores médios de tolerância inferiores aos dos Métodos I e II. As diferenças nos valores de tolerância encontradas para al gumas classes de solo neste método em relação ao Método II são explicadas pel os diferentes valores de ponderação $(1,00,0,85$ e $0,70)$ utilizados para os distintos teores de matéria orgânica e graus de permeabilidade dos solos, em relação aos val ores de ponderação $(1,15,1,00$ e 0,85) utilizados por Galindo \& Margol is (1989) para essas duas características dos solos.

Os valores de tolerância obtidos pelo Método I (Quadro 4) revelaram ampla variação, de 0,20 a $1,16 \mathrm{~mm}^{2} \mathrm{no}^{-1}$, como demonstram os val ores do erropadrão da média, em cujo interval o o método detectou dois grupos de classes de sol o com distinta tolerância (Quadro 7), conforme discutido anteriormente. Pelo Método II (Quadro 5), essa variação também foi ampla, de 0,21 a 1,16 $\mathrm{mm} \mathrm{ano}^{-1}$, indicada igualmente pelo erro-padrão da média, no qual foram detectados também dois grupos de classes de solo com valores distintos detolerância (Quadro 7), omesmo ocorrendo no Método III (Quadro 6), no qual as tolerâncias variaram de 0,15 a 1,13 mm ano-1 (Quadro 7), e menor variaçãonos val ores do erro-padrão da média. I sso mostra que o Método III apresentou valores médios de tolerância de perda de solo menores do que o Método II e, este, praticamente iguais aos do Método I, para as classes de solo estudadas. Assim, é possível dizer que o Método III foi o mais rigoroso para estabel ecer o limite de perda de solo, uma vez que ele, para algumas classes, apresentou valores de tolerância de perda de solo inferiores aos dos Métodos I ell (Quadro 7).

Quadro 6. Tolerâncias de perda de solo por erosão $\left(\mathrm{mm} \mathrm{ano}^{-1}\right)$ para os perfis de solo estudados, esti madas por meio do Método proposto por Galindo \& Margolis (1989), modificado pelos autores quanto aos interval os da relação textural e incluído o teor de argila no horizonte A como foi feito no Método II e, ainda, modificado pelos autores quanto aos fatores de ponderação para o teor de matéria orgânica e grau de permeabilidade, denominado Método III

\begin{tabular}{llllllllllll}
\hline & \multicolumn{1}{c}{ Número de perfis } & & & \\
Classe & 1 & 2 & 3 & 4 & 5 & 6 & 7 & 8 & 9 & 10 & Média Erro-padrão
\end{tabular}

\begin{tabular}{|c|c|c|c|c|c|c|c|c|c|c|c|c|}
\hline LB & 0,72 & 1,00 & - & - & - & - & - & - & - & - & 0,89 & 0,101 \\
\hline LBR & 1,00 & 1,00 & 1,00 & - & - & - & - & - & - & - & 1,13 & 0,075 \\
\hline LR & 1,00 & 0,70 & - & - & - & - & - & - & - & - & 0,86 & 0,106 \\
\hline LE & 0,85 & 0,85 & 1,00 & 1,00 & - & - & - & - & - & - & 0,93 & 0,038 \\
\hline LV & 0,85 & 0,77 & 0,77 & - & - & - & - & - & - & - & 0,84 & 0,033 \\
\hline PV & 0,49 & 0,61 & 0,61 & 0,44 & 0,63 & 0,70 & 0,49 & 0,60 & 0,48 & 0,60 & 0,58 & 0,028 \\
\hline PE & 0,43 & 0,42 & 0,65 & - & - & - & - & - & - & - & 0,52 & 0,062 \\
\hline TB & 0,85 & 0,85 & 1,00 & 0,85 & 1,00 & 0,85 & - & - & - & - & 1,05 & 0,068 \\
\hline TBR & 0,85 & 0,85 & 0,77 & - & - & - & - & - & - & - & 0,91 & 0,075 \\
\hline TVB & 0,85 & 1,00 & 1,00 & - & - & - & - & - & - & - & 1,03 & 0,062 \\
\hline TR & 0,70 & 1,00 & - & - & - & - & - & - & - & - & 0,87 & 0,107 \\
\hline BV & 0,46 & 0,70 & - & - & - & - & - & - & - & - & 0,65 & 0,098 \\
\hline $\mathrm{CH}$ & 0,72 & 0,85 & 0,72 & 0,60 & 0,83 & 0,53 & 0,77 & 0,72 & 0,81 & 0,77 & 0,74 & 0,030 \\
\hline $\mathrm{Ce}$ & 0,54 & 0,60 & - & - & - & - & - & - & - & - & 0,60 & 0,030 \\
\hline $\mathrm{CBH}$ & 0,85 & 0,54 & - & - & - & - & - & - & - & - & 0,71 & 0,110 \\
\hline$C$ & 0,65 & 0,66 & 0,59 & 0,72 & 0,46 & - & - & - & - & - & 0,63 & 0,040 \\
\hline $\mathrm{RH}$ & 0,09 & 0,47 & 0,14 & 0,09 & - & - & - & - & - & - & 0,18 & 0,080 \\
\hline $\mathrm{R}$ & 0,07 & 0,36 & 0,09 & - & - & - & - & - & - & - & 0,15 & 0,078 \\
\hline $\mathrm{AQ}$ & 0,28 & 0,15 & 0,15 & 0,14 & - & - & - & - & - & - & 0,18 & 0,029 \\
\hline
\end{tabular}

LB, LBR, LR, LE e LV: Latossolos Bruno, Bruno/Roxo, Roxo, Vermelho-Escuro e Vermelho-Amarelo, respectivamente; PV e PE: Podzólicos Vermelho-Amarelo e Vermelho-Escuro, respectivamente; TB, TBR, TVB e TR: Terras Bruna, Bruna/Roxa, Vermelha/ Brunada e Roxa Estruturadas, respectivamente; BV: Brunizém Avermel hado; $\mathrm{CH}, \mathrm{Ce}, \mathrm{CBH}$ e C: Cambissolos Húmicos eutróficos e Bruno Húmico, e Cambissolo, respectivamente; RH e R: Litólico Húmico e Litólico, respectivamente; AQ: Areia Quartzoza. 


\section{Quadro 7. Valores médios de tolerância de perda de solo por erosão $\left(\mathrm{mm}^{\mathrm{ano}} \mathrm{o}^{-1}\right)$ para as princi pais classes de solo do estado de Santa Catarina, estimados por meio dos Métodos I, II e III}

\begin{tabular}{|c|c|c|c|}
\hline Classe de solo & Método I & Método II & Método III \\
\hline & \multicolumn{3}{|c|}{$-\mathrm{mm}$ ano-1 } \\
\hline Terra Bruna Estruturada & $1,16 \mathrm{Aa}$ & $1,16 \mathrm{Aa}$ & 1,05 Babc \\
\hline Latossolo Bruno/Roxo & $1,13 \mathrm{Aa}$ & $1,13 \mathrm{Aa}$ & $1,13 \mathrm{Aa}$ \\
\hline Terra Vermelha/Brunada Estruturada & $1,11 \mathrm{Aa}$ & $1,11 \mathrm{Aa}$ & $1,03 \mathrm{Aab}$ \\
\hline Terra Bruna/Roxa Estruturada & $1,07 \mathrm{Aa}$ & $1,07 \mathrm{Aa}$ & $0,91 \mathrm{Babcd}$ \\
\hline L atossolo Vermel ho-Amarelo & $1,07 \mathrm{Aa}$ & $0,99 \mathrm{Aab}$ & $0,84 \mathrm{Babcd}$ \\
\hline Latossolo Bruno & $1,01 \mathrm{Aa}$ & $1,01 \mathrm{Aa}$ & $0,89 \mathrm{Babc}$ \\
\hline Latossolo Vermel ho-E scuro & $1,01 \mathrm{Aa}$ & $1,01 \mathrm{Aa}$ & $0,93 \mathrm{Bab}$ \\
\hline Latossolo Roxo & $1,00 \mathrm{Aa}$ & $1,00 \mathrm{Aa}$ & $0,86 \mathrm{Babc}$ \\
\hline Cambissolo Húmico & $0,93 \mathrm{Aa}$ & $0,90 \mathrm{Aab}$ & 0,74 Bbcde \\
\hline Cambissolo & $0,91 \mathrm{Aab}$ & $0,91 \mathrm{Aab}$ & 0,71 Bcdef \\
\hline Cambissolo eutrófico & $0,91 \mathrm{Aab}$ & $0,84 \mathrm{Babc}$ & 0,63 Cdef \\
\hline Terra Roxa Estruturada & $0,89 \mathrm{Aab}$ & $0,87 \mathrm{Aab}$ & $0,87 \mathrm{Aabc}$ \\
\hline Podzól ico Vermelho-E scuro & $0,86 \mathrm{Aab}$ & $0,75 \mathrm{Bbc}$ & $0,52 \mathrm{Cf}$ \\
\hline Cambissolo Bruno Húmico & $0,86 \mathrm{Aab}$ & $0,82 \mathrm{Aabc}$ & 0,60 Bef \\
\hline Podzól ico Vermelho-Amarelo & $0,81 \mathrm{Aab}$ & $0,75 \mathrm{Bbc}$ & 0,58 Cef \\
\hline Brunizem Avermelhado & $0,79 \mathrm{Ab}$ & $0,72 \mathrm{AC}$ & 0,65 Aef \\
\hline Areia Quartzoza & $0,32 \mathrm{AC}$ & $0,26 \mathrm{Ad}$ & $0,18 \mathrm{Bg}$ \\
\hline Litólico Húmico & $0,20 \mathrm{AC}$ & $0,21 \mathrm{Ad}$ & $0,18 \mathrm{Ag}$ \\
\hline Litólico & $0,21 \mathrm{AC}$ & $0,21 \mathrm{Ad}$ & $0,15 \mathrm{Ag}$ \\
\hline Média & 0,86 & 0,83 & 0,71 \\
\hline C.V. (\%) & 14,9 & 15,2 & 14,3 \\
\hline
\end{tabular}

Valores seguidos da mesma letra maiúscula, na linha, para comparar métodos, e minúscula, na coluna, para comparar classes de solo, não diferem estatisticamente por Duncan a $5 \%$.

Os PodzólicoseCambissolos eutróficos apresentaram valores de tolerância menores no Método II do que no Método I (Quadro 7), dada a inclusão do teor de argila do horizonte $\mathrm{A}$ e dos diferentes valores de intervalos de relação textural como fatores de ponderação dos limites de perda, os quais não afetaram as demais classes de sol o. O M étodo II não diferiu sensivel mente do método I na estimativa das tolerâncias de perda, principalmente pel o fato deser grande parte dos solos catarinenses composta de Latossolos, Terras Estruturadas, Cambissolos, Cambissolos Húmicos e Cambissolos Brunos Húmicos, a maioria deles de textura argil osa e muito argilosa. Dequalquer modo, a inclusão desses fatores de ponderação deve aumentar a sensibilidade do método, particularmente quando a população de solos apresentar maior variação declasses texturais no horizonte superficial. Tal consideração é importante, já quea maior parte dos sol os das demais regiões tropicais e subtropicais do Brasil é composta principal mente de Latossol os e Podzólicos.

Os val ores médios de tolerância de perda de solo obtidos no Método III foram cerca de 13 e 17\% menores do que os dos Métodos II el , respectivamente (Quadro 7). Tais diferenças foram expressivamente maiores do que a obtida nos Métodos II e I, a qual foi de aproximadamente 4\%. Assim, a maioria dos
Latossolos e todas as Terras Brunas, Podzólicos, Cambissolos e Areias Quartzozas apresentaram tolerâncias menores pelo Método III do que pelos Métodos II e I. Isso indica que a inclusão de maior número de atributos do solo e de distintas características como fatores de ponderação dos limites de tolerância de perda, além de aumentar a sensibilidade desse método, também conferiu maior grau de restrição aos limites de perda, tornando-o conservacionista neste aspecto. Assim, ele pode ser sugerido para estimar a tolerância de perda de solo para as referidas classes.

LatossoloBruno/Roxo, Terra Vermelha/Brunada, Terra Roxa E struturada, Brunizém Avermel hado e Sol os Litól icos apresentaram os mesmos valores de tolerância nos três métodos estudados (Quadro 7). Isso significa que, para estas classes de solo, qualquer dos métodos estudados pode ser utilizado para predizer a tolerância de perda de solo por erosão.

Todos os métodos utilizados para estimar a tol erância de perda de sol o por erosão nestetrabal ho são empíricos, razão por que os valores estimados podem ser questionados sob diversos aspectos. Sua principal fragilidadeéa consideração de um período fixo de mil anos como sendo necessário para desgastar completamente uma camada de, até, um 
metro de solo, o que certamente restringe o tempo de vida útil do sol o a cerca de 10 ou 20 gerações, no caso de se manter uma perda média anual de solo dentro da tolerância estimada. Embora não seja considerada no cálculo, a formação de solo nesse período ocorre efetivamente e a certa taxa, variável para cada sol o; portanto, esta, mesmo quando baixa, poderá garantir a manutenção da capacidade produtiva do sol o para valores além daquele limite. A inclusão de maior número de variáveis e de novos fatores de ponderação do seu efeito na definição dos limites máximos de perda, sempre que seus valores forem inferiores à unidade, também acrescentam níveis de restrição aos limites de perda. Todavia, dado seu caráter empírico, dificilmente traduzirão com fidelidade o que real mente seria perda tolerável, uma vez que esse conceito ainda carece de uma definição exata, tanto no aspecto relativo à manutenção da capacidade produtiva do solo como da preservação ambiental.

Conhecer os limites de perda de solo toleráveis para as condições catarinenses é importante para comparar a eficácia relativa de controle da erosão hídrica dos sistemas de manejo do solo atualmente utilizados. Entretanto, a seleção de métodos necessitava estar em consonância com o reduzido número de informações, na forma de parâmetros, acerca dos perfis de solo disponíveis. Por isso, optouse, num primeiro momento, por aplicar essas informações em métodos sintéticos já disponíveis, aos quais se introduziram modificações para tornálos mais rigorosos e, ou adaptados às condições de solos do sul do Brasil, com base em critérios estabelecidos pelos autores, definidos pela sua experiência. Portanto, os val ores estimados devem ser interpretados com cautela, já que representam uma primeira aproximação da definição de limites de tolerância de perda de solo para as condições catarinenses, passíveis de modificação na medi da da evolução do conhecimento.

Os val ores de tolerância de perda de sol o obtidos pelos três métodos estudados variaram de 1,16 mm ano-1, no caso da Terra Bruna Estruturada, a 0,15 mm ano-1, no caso dos Litólicos, na média das classes estudadas (Quadro 7). I sto eqüivale a uma perda máxima permitida de uma camada de 11,6 e 1,5 amem 100 anos, respectivamente, para essas dasses de solo. Considerando uma densidade de solo de $1,250 \mathrm{~g} \mathrm{~cm}^{-3}$, essas perdas seriam, respectivamente, da ordem de 1.450 e $188 \mathrm{Mg} \mathrm{ha}^{-1}$ de sol o a cada 100 anos ou, respectivamente, de 14,5 e 1,88 $\mathrm{Mg} \mathrm{ha}^{-1}$ ano-1. Esses valores provavel mente excedem os níveis de perda de solo permitidos para não causar contaminação da água pelos produtos da erosão hídrica, cujos critérios e limites ainda carecem de definição. Portanto, os métodos e características utilizadas nesteestudo provavel mente são aplicáveis apenas para estimar as tolerâncias de perda de solo por erosão visando manter a capacidade produtiva do solo para fins agrícolas.

\section{CONCLUSÕES}

1. Os valores de tolerância de perda de solo obitidos pelos três métodos estudados, para os princi pais sol os do estado de Santa Catarina, variam de 0,15 a 1,16 mm ano-1; pelo Método I, essa variação é de 0,20 a 1,16 mm ano-1, sendo de 0,21 a $1,16 \mathrm{~mm}^{2} \mathrm{ano}^{-1}$ pelo Método II e de 0,15 a $1,13 \mathrm{~mm}^{2} \mathrm{no}^{-1}$ pel o Método III , na média das classes de sol o estudadas.

2. O Método III, neste estudo representado pelo método proposto por Galindo \& Margolis (1989), modificado quanto aos interval os da relação textural e incluído o teor de argila no horizonte $\mathrm{A}$ e, ainda, modificado quanto aos fatores de ponderação para o teor de matéria orgânica e grau de permeabilidade, é mais rigoroso do que os Métodos I ell e, por isso é sugerido para estimar a tolerância de perda de solo da maioria dos Latossolos e de todas as Terras Brunas, Podzólicos, Cambissol o eAreias Quartzosas do estado de Santa Catarina; para as demais classes de solo desse estado, a tolerância de perda de solo pode ser estimada por qualquer dos métodos estudados.

\section{LITE RATURA CITADA}

ALMEIDA, J .A. Evolução mineralógica dos solos e relação solosuperfícies geomórficas em áreas de encostas basálticas no Vale do Rio do Peixe, SC. Lages, Departamento de Solos, CAV/UDESC, 1997. 11p. (Mimeografado)

ALMEIDA, J .A. \& BERTOL, I. Caracterização física e química dos solos do Estado de Santa Catarina. Etapa I: solos do planalto catarinense. Lages, Departamento de Solos, CAV/ UDESC, 1987. 20p. (Mimeografado)

ALMEIDA, J .A. \& MAÇANEIRO, K.C. Caracterização física, química e mineralógica de solos brunos e vermelhos estruturados desenvolvidos de rochas pelíticas para fins de conceituação taxonômica. Lages, Departamento deSolos, CAV/UDESC, 1996. 21p. (Mimeografado)

ALMEIDA, J .A.; KÄMPF, N. \& ALMEIDA, R. Caracterização mineralógica de cambissolos originados de rochas pelíticas nos patamares do Alto Rio Itajaí e no Planalto de Lages (SC). R. Bras. Ci. Solo, 21:181-190, 1997.

BOGNOLA, I.A. Caracterização química, física e mineralógica desol os intermediários entre Latossol os brunos e Latossol os roxos. Viçosa, U niversidade F ederal de Viçosa, 1995. 205p. (Tese de Mestrado)

BROWNING, G.M.; PARISH, G.L. \& GLASS, J . A method for determining the use and limitation of rotation and conservation practices in the control of soil erosion in lowa. J . Am. Soc. Agron., 39:65-73, 1947.

FREIRE, O. \& VASQUES FILHO, J. Tolerância de perdas para os solos de Piracicaba. R. Agric., 53:261-267, 1978. 
GALINDO, I.C. \& MARGOLIS, E. Tolerância de perdas por erosão para sol os do Estado de Pernambuco. R. Bras. Ci. Solo, 13:95100, 1989.

GOMES, F.P. Curso de estatística experimental. 11. ed. Piracicaba, Nobel, 1985. 466p.

J OHNSON, L.C. Soil loss tolerance: Fact or myth? J . Soil Water Conserv., 42:155-160, 1987.

LOMBARDI NETO, F . \& BERTONI, J . Tolerância de perdas de terra para sol os do estado deSão Paulo. Campinas, Instituto Agronômico, 1975. 12p. (Boletim Técnico, 28)

RENARD, K.G.; FOSTER, G.R.; WEESIES, G.A.; McCOOL, D.R. \& YODER, D.C. Predicting soil erosion by water: a guide to conservation planning with the revised universal soil loss equation (RUSLE). Washington D.C., Departament of Agriculture, 1997. 404p. (Agriculture Handbook, 703)
SMITH, D.D. Interpretation of soil conservation data for field use. Agr. Eng., 22:173-175, 1941.

SMITH, D.D. \& WHITT, D.M. Evaluating soil losses from field areas. Agr. Eng., 29:394-396, 398, 1948.

SPAROVEK, G. \& van LIER, J.Q. Definition of tolerable soil erosion values. R. Bras. Ci. Solo, 21:467-471, 1997.

UNIVERSIDADE FEDERAL DE SANTA MARIA - UFSM. Levantamento de reconhecimento dos solos do Estado de Santa Catarina. Santa Maria, 1973. 2v.

WISCHMEIER, W.H. \& SMITH, D.D. Predicting rainfall erosion losses; a guide to conservation planning. Washington D.C., Departament of Agriculture, 1978. 58p. (Agriculture Handbook, 537) 